\title{
Design Principles and User Interfaces of Erkki Kurenniemi's Electronic Musical Instruments of the 1960's and 1970's
}

\author{
Mikko Ojanen \\ Department of \\ Musicology \\ P.O. Box 35 \\ 00014 University of \\ Helsinki \\ Finland
}

\author{
Jari Suominen \\ Department of \\ Computer Science \\ P.O. Box 68 \\ 00014 University of \\ Helsinki \\ Finland
}

\author{
Titti Kallio \\ TeliaSonera \\ P.O. Box 585 \\ 00051 Sonera
}

Mikko.Ojanen@helsinki.fi Jari.Suominen@helsinki.fi $\begin{array}{ccc}\text { Finland } & 00014 \text { University of } \\ \text { Titti.Kallio@teliasonera.com } & \begin{array}{c}\text { Helsinki } \\ \text { Finland }\end{array}\end{array}$

\author{
Kai.Lassfolk@helsinki.fi \\ Kai Lassfolk \\ Department of \\ Musicology \\ P.O. Box 35 \\ Helsink \\ Finland
}

\begin{abstract}
This paper presents a line of historic electronic musical instruments designed by Erkki Kurenniemi in the 1960's and 1970's. Kurenniemi's instruments were influenced by digital logic and an experimental attitude towards user interface design. The paper presents an overview of Kurenniemi's instruments and a detailed description of selected devices. Emphasis is put on user interface issues such as unconventional interactive real-time control and programming methods.
\end{abstract}

\section{Keywords}

Erkki Kurenniemi, Dimi, Synthesizer, Digital electronics, User interface design

\section{INTRODUCTION}

Erkki Kurenniemi (b. 1941) is one of the leading pioneers of Finnish electroacoustic music. A musical instrument designer, composer, and multimedia artist, Mr. Kurenniemi played a central role in the Finnish avant-garde music scene in the 1960's and early 1970's. During that time, he built a series of unique electronic musical instruments, each of which can be regarded as unconventional also from today's perspective. He also founded the first and still operational Finnish electronic music studio at the Department of $\mathrm{Mu}-$ sicology, University of Helsinki. Kurenniemi collaborated with several composers and artists including Ralph Lundsten, Erkki Salmenhaara, Osmo Lindeman, Henrik Otto Donner, Jukka Ruohomäki, M.A. Numminen, and the Norwegian theater company Scene 7.

Kurenniemi's best-known achievement as an instrument maker is a line of electronic music devices named Dimi (Digital Musical Instrument). As an instrument designer, Kuren-

Permission to make digital or hard copies of all or part of this work for personal or classroom use is granted without fee provided that copies are not made or distributed for profit or commercial advantage and that copies bear this notice and the full citation on the first page. To copy otherwise, to republish, to post on servers or to redistribute to lists, requires prior specific permission and/or a fee.

NIME07, June 6-10, 2007, New York, USA

Copyright 2007 remains with the author(s). niemi's particular interests were in digital logic and its application to user interface design. In the mid 1970's, Kurenniemi left the electroacoustic music scene to work for the Finnish industry specializing in industrial automation and robotics. Later he worked as a researcher in Heureka, The Finnish Science Centre. Kurenniemi became a well-known specialist and visionary of modern technology and appeared in many television and newspaper interviews describing his futuristic ideas and innovations. In the 1980's Kurenniemi returned to music-related research by developing a new theory of tonal harmony [5].

The early 2000's saw a renewed interest in Kurenniemi's early work. In 2002, Mika Taanila directed the documentary film Future Is Not What It Used To Be [16] about Kurenniemi's work and philosophy. Taanila also compiled a collection of Kurenniemi's compositions on a CD entitled Erkki Kurenniemi: Recordings 1963-1973 [6] released by a Finnish record company Siboney in 2002. Kurenniemi's instruments, Dimi-A in particular, have been on display at art exhibitions in both London and Helsinki. In recent years, Kurenniemi has performed live in Venice, Berlin, and Helsinki playing his instruments with artists such as the experimental electronic music group Pan Sonic. In 2003, Kurenniemi received the Finland Prize (Suomi-palkinto) from the Finnish Ministry of Education for his work as an artist and researcher of the future.

In this paper we will first present Kurenniemi's instruments in general and then take a closer look at some of them. Both technical and user interface issues of the instruments are discussed. The methods we have used include interviews, hands-on experimentation with the instruments and study of the remaining technical documentation. The conducted interviews consist of several discussions with Kurenniemi himself, composer Jukka Ruohomäki, artist Mauri Antero Numminen and engineer Hannu Viitasalo. Mr. Ruohomäki and Mr. Numminen were among the first users of Kurenniemi's instruments and Mr. Viitasalo worked as an electrical engineer in Kurenniemi's company Digelius Electronics Finland Inc.

In 2002, the remaining instruments in Finland, as well as their contemporary technical documentation, were gathered and stored in the University of Helsinki Electronic Music Studio. Also some restoration work was done in collaboration with the Finnish Museum of Contemporary Art, Ki- 
Proceedings of the 2007 Conference on New Interfaces for Musical Expression (NIME07), New York, NY, USA

\begin{tabular}{|l|l|r|l|l|}
\hline Instrument & Year & Qty & Description & Working condition \\
\hline Integrated Synthesizer & $1964-$ & 1 & Modular synthesizer with digital and analog modules. & Out of order \\
Electric Quartet & 1968 & 1 & Collective instrument for four players. & Good \\
Andromatic & 1968 & 1 & Polyphonic synthesizer with 10-step sequencer. & Full \\
Dico & 1969 & 1 & Synthesizer with 12-step sequencer and digital memory. & Full \\
Dimi-A & 1970 & 2 & Programmable 256-step sequencer with digital memory. & Partial \\
Dimi-O & 1971 & 1 & Synthesizer with a video interface. & Good \\
Dimix & 1972 & 1 & Electronic patchbay with video output. & Poor \\
Dimi-S & 1972 & 2 & An instrument controlled by skin resistance of players. & Full \\
Dimi-T & 1973 & 1 & A brainwave controlled instrument. & Out of order \\
Dimi-U & - & - & Combination of Dimi-A and Dimi-O. & Never constructed \\
Dimi-6000 & 1973 & 2 & Computer controlled analog synthesizer. & OS destroyed \\
\hline
\end{tabular}

Table 1: Erkki Kurenniemi's Electronic Musical Instruments

asma. The authors Mikko Ojanen and Jari Suominen have played Kurenniemi's instruments in concerts together with Kurenniemi. The documentation includes schematics and Kurenniemi's sketches. It lacks, however, explicit operating instructions. Therefore, much of the playing techniques had to be revived by experiment.

This is the first study of Kurenniemi's instrument published in English. Former studies of Kurenniemi's instruments, published in Finnish, include Kalev Tiits's M.A. thesis [17] and our recently published article in the Musiikki musicological periodical [12]. Also, related to the subject is Mikko Ojanen's M.A. thesis [11] about Jukka Ruohomäki's music. Kurenniemi's earliest instruments are also mentioned in Petri Kuljuntausta's book On/Off [2] about early Finnish electronic music.

\section{A BRIEF HISTORY OF KURENNIEMI'S INSTRUMENT DESIGN}

The Electronic Music Studio of the Department of Musicology, University of Helsinki can be regarded as the first "instrument" designed and built by Kurenniemi. Instead of a conventional tape music studio of the early 1960's Kurenniemi designed his studio as an automated composition system. As the heart of the studio Kurenniemi built a device called Integrated Synthesizer (1964-), which consisted of three separate units: a tone generator, a mixer and a filter. Integrated Syntheziser was intended to also control the studio tape recorders. The vision of a fully automated studio was never completed. However, Integrated Synthesizer remained in use for a few years. In the late 1960's, Kurenniemi envisioned a mainframe computer based composition system with terminals distributed around the university. Amidst his ambitious studio design plans Kurenniemi built three custom made synthesizers: Electric Quartet, Andromatic, and Dico. [12]

Kurenniemi built Electric Quartet - also the name of the band that used the instrument - for the Finnish underground artist Mauri Antero Numminen (b. 1940) in 1968. This "collective" instrument consists of a main unit (with tone generators and a sequencer) and a set of controllers (Melody machine, Electrical trumpet, Violin machine, Drum machine and a controller for distorting the vocalist's voice). Numminen - the singer and leader of the band - aimed to provoke the audience and his request was to have a somewhat chaotic instrument to reach this goal. The repertoire of Electric Quartet was limited to one piece entitled Kaukana väijyy ystäviä (Far away lurk some friends). Their finest hour - according to Numminen - was in Bulgaria 1968 where their performance for an audience of 4000 people was intercepted by the concert organizers $[2,10]$.

Andromatic (1968) was designed in collaboration with the Swedish composer Ralph Lundsten (b. 1936). Andromatic is a polyphonic synthesizer with a 10-step sequencer where every step has its own oscillator. Initially, the instrument was designed for the Emotion exhibition in the Samlaren art gallery in Stockholm. In the exhibition it played music and controlled the lights of a sculpture. The name of the instrument originates from the name of the Lundsten's studio, Andromeda, where Andromatic is also currently located. [12] The third custom made instrument, Dico (1969) was designed for the Finnish composer Osmo Lindeman (19291987). Dico is described below in more detail.

In 1970, Kurenniemi founded Digelius Electronics Finland Inc. with Jouko Kottila and Peter Frisk as his partners. Under Digelius Kurenniemi designed a line of electronic music devices including five synthesizers: Dimi-A (1970), Dimi-O (1971), Dimi-S (1972), Dimi-T (1973) and Dimi-6000 (1973), as well as the digitally controlled mixing console and patchbay Dimix (1972). [12]

After Dimi-O Kurenniemi started to design a new instrument called Dimi-U. There, his aim was to combine the strengths of both Dimi-A and Dimi-O. However, the project was halted when Kurenniemi got interested in designing a microprocessor controlled synthesizer which eventually became Dimi-6000. [12]

Kurenniemi's instruments are listed in Table 1.

\section{DESCRIPTIONS OF SELECTED INSTRU- MENTS}

Below, some of Kurenniemi's instruments are described in more detail. The focus is on the best known instruments of the Dimi series: Dimi-A, Dimi-O, Dimi-S and Dimi-T. Also included is a description of one of the earlier instruments, Dico. It can be seen as a starting point of Kurenniemi's more experimental user interface design. A noticeable aspect in Kurenniemi's design work is its evolutionary nature. Many basic ideas of the early instruments emerged in advanced forms later on. Dico, for example, shares the same design core with Dimi-A and Dimi-O consisting of static oscillators combined with a frequency division network and analog filters. As synthesizers, Dimi-S and Dimi-T are more like musical toys than serious instruments. However, they represent an interesting experimental approach to instrument control. 


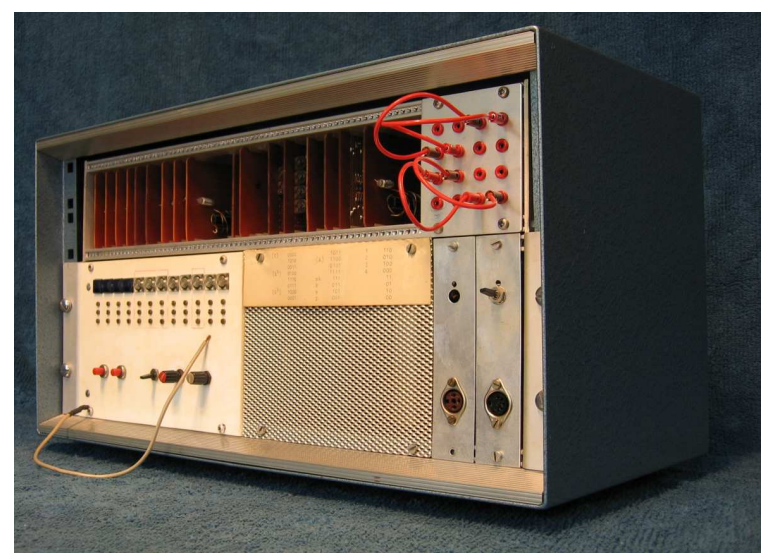

Figure 1: Dico. Note the grounded cable which has replaced the metal brush.

\subsection{Dico}

Osmo Lindeman switched from composing instrumental music to purely electroacoustic music in the late 1960's and built a private studio for this purpose. To complement a set of tape recorders and sound processors he needed an electronic tone generator. Lindeman ordered an electronic instrument from Kurenniemi and after a few consultations with Lindeman Kurenniemi built Dico (Digitally controlled oscillator) (Figure 1). [12]

Lindeman's basic idea was that the instrument should be a programmable sequencer. Kurenniemi's answer was a monophonic synthesizer equipped with a 12-step sequencer. Dico's interface consists of a $4 \times 4$ point patchbay, a matrix of three rows by twelve columns of metal pins, a row of light bulbs (one bulb placed above each pin column), a special metal brush and a set of switches, buttons and potentiometers to start and stop the sequencer and to control pitch and tempo. The state of each sequencer step is represented by 10 light bulbs (the remaining two were left as a 'future expansion'). The sequencer is programmed in "step time" by using the metal brush to connect a pin in the middle row to either the pin above it (setting a bit on) or the pin below it (setting the bit off). On each step the user can adjust the diatonic pitch (four bits), octave range (three bits), articulation (two bits) and the output channel (one bit). Assignment of the signal to one of the instrument's two filter banks can be made at the patchbay.

The idea of the sequencer is based on Kurenniemi's experience with early digital computers. The sequencer design is basically identical to a primitive computer with twelve tenbit memory locations. The user can edit the bits of each memory location by first selecting the memory location and then altering the bits individually with switches. The light bulb on the top of each switch tells the state of each bit.

The use of the metal brush (later replaced with a grounded wire) adds randomness to Dico's operation. One way of playing it is to start the sequencer with high tempo to produce an arpeggio. If the player touches the metal pins with the brush lightly or quickly enough, some bits in the sequence are changed while some are not. This makes it possible to 'crossfade' from one chord to another slowly and somewhat randomly in a similar way to a painter layering brushstrokes on a canvas one stroke over another.

\subsection{Dimi-A}

Dimi-A (Figure 2) is a two-voice programmable synthesizer and it is probably the best-known of Kurenniemi's instruments. Dimi-A was built as a research project where the focus was to explore the potential applications of the digital techniques in producing electroacoustic music. [4]

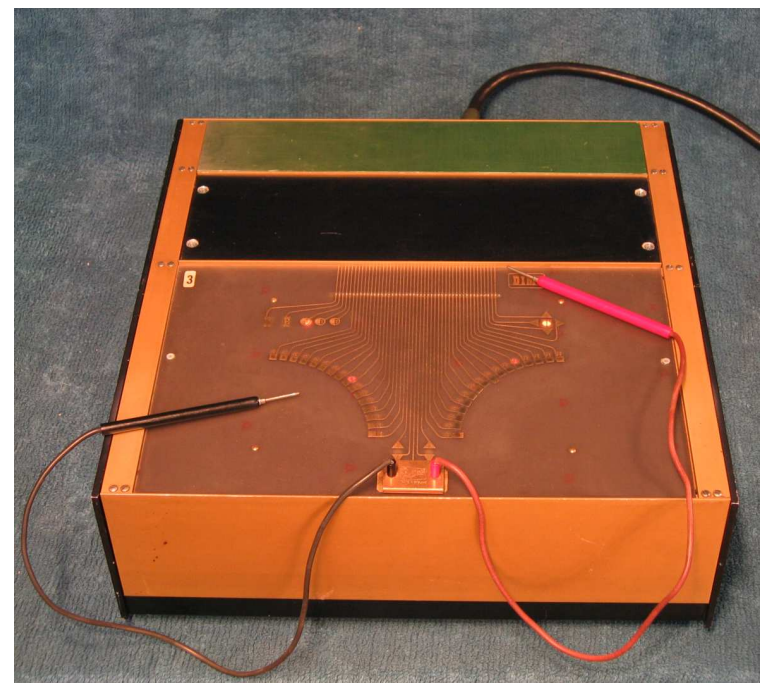

Figure 2: Dimi-A

Dimi-A is programmed by touching metal contacts on the instrument's touchpad, with two metal sticks (Figure 2). The absence of an alphanumeric, let alone graphic, display for the user interface makes the programming task fairly difficult because the memory contents can only be checked by listening. Also, the memory is volatile with no mass storage backup, although Kurenniemi planned to make a cassette tape interface as an upgrade. [4] Despite these weaknesses the instrument was used even for live improvisations.

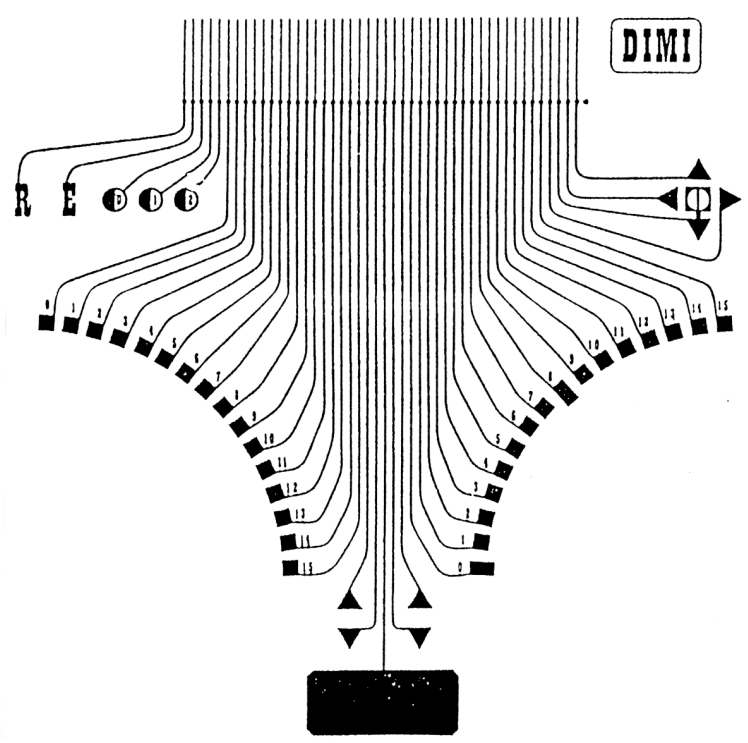

Figure 3: Layout of Dimi-A's touchpad 
Dimi-A has two operational modes, "play" and "command", between which the user can toggle by touching the arrow-shaped plates at the bottom of the touchpad (Figure 3 ). In the "play" mode the user can start or stop a sequence by using the four arrow plates on the top right. The user can also jump to any step of the sequence by selecting a bar with the numbered plates on the left and a step with the numbered plates on the right. In the "command" mode the left-hand numbered plates will define a parameter number and the right-hand plates the parameter value. These commands can be stored at any step of the sequence by using the 'R'-plate on the left. Each step can also have multiple commands stored in it. Other plates on the top left are for erasing the memory. Dimi-A has dedicated parameters for (diatonic) pitch, volume, filters, vibrato, oscillator on/off, ring modulation, sequence jumps, and tempo.

Dimi-A was Kurenniemi's first instrument built for the commercial market. To promote the instrument Digelius Electronics released the single entitled Dimi 1: Dimi is born (Musica DSS-1) in 1970. The record included Kurenniemi's arrangement of Johann Sebastian Bach's Inventio no. 13 in A minor (BWV 784) entitled Inventio-Outventio. Bach's two-voice composition provided optimal material for demonstrating the capabilities of the instrument. The B side of the single contained Jukka Ruohomäki's composition What is time?. [15, 12]

Kurenniemi presented Dimi-A to Peter Zinovieff, a British composer and synthesizer designer, who stated that the instrument was quite an attractive device, but its sound quality was poor [3]. Despite the marketing efforts, only two Dimi-A units were manufactured. One of them is in the University of Helsinki Electronic Music Studio. The other one was sold to Ralph Lundsten, who later donated it to the Musikmuseet, The Stockholm Music Museum. However, with the attention gained by Dimi-A Kurenniemi and Digelius Electronics got funding from SITRA, The Finnish National Fund for Research and Development, which they spent on new instrument projects. [12]

\subsection{Dimi-O}

With the funding from SITRA the prototype of a videocontrolled organ, Dimi-O (Figure 4) was completed in April 1971. Besides Kurenniemi, the electrical engineer Hannu Viitasalo played an important role on designing and constructing the instrument. $[4,19]$

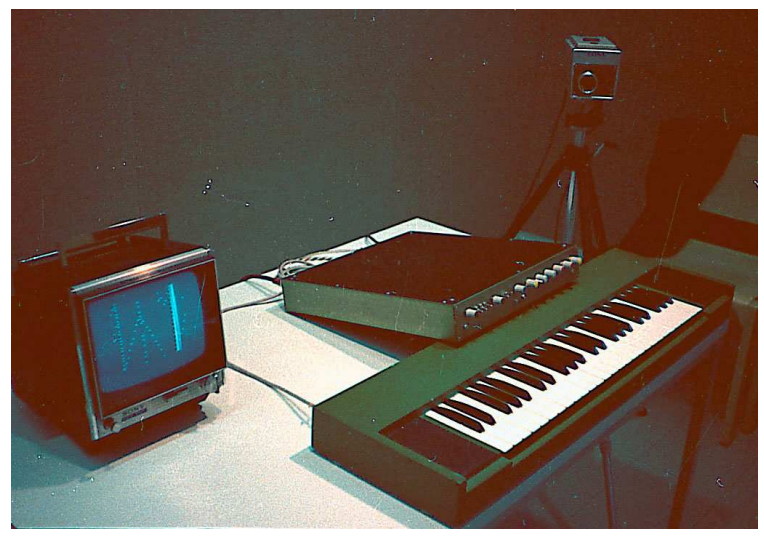

Figure 4: Dimi-O
Dimi-O includes a four-octave conventional electric organ keyboard and a memory unit with a 32 -step sequencer. The memory locations are presented on a television screen from which the player can read the contents of the memory. A cursor running over the screen tells which location is played at the moment. On the screen the 32 -step sequence is presented horizontally and the four-octave key range (i.e. 48 pitches) is presented vertically. In this respect Dimi-O was easier to use than Dimi-A.

The unconventional part of the instrument is the optical input by a television or video camera (Figure 5). The picture captured by the camera is converted to black and white and can thereafter be transferred into the memory unit and used as a control signal. Adjusting the contrast of the picture affects the instrument's response to the picture. When brightness is set to maximum the instrument plays a complete four-octave diatonic cluster. When brightness is reduced only some of the notes are played.

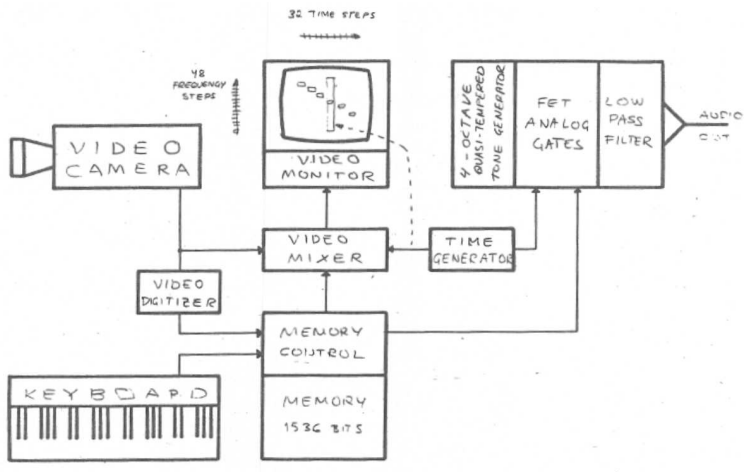

Figure 5: Dimi-O block diagram

After the prototype of Dimi-O was completed, Kurenniemi listed potential usages of the instrument[4]: First of all, it can be used in a studio as a tone generator. There, an obvious application is to read graphic music notation through the video input. Secondly, Dimi-O can be used as a solo instrument or in collaboration with orchestras. Kurenniemi also described a more avant-garde way of use of the instrument: e.g. in ballet or at the theater with the camera shooting dancers or actors as well as in experimental films where all the changes in the picture could be transformed into music. Eventually, Dimi-O was used even in a psychological test in the University of Oslo, Norway. There, Dimi-O's camera was shooting the testees' faces while they were interpreting Rorschach pictures.

A somewhat similar optical input method emerged again later in the software intrument Dimi- $\mathrm{H}^{1}$ (2004).

\subsection{Dimi-S and Dimi-T}

In the summer of 1968 Kurenniemi visited an electroacoustic music conference organized by Teatro Comunale in Florence, Italy. During the conference Kurenniemi was introduced to Manford L. Eaton's ideas of biofeedback as a source of musical or compositional material. Two of Kurenniemi's instruments - Dimi-S and Dimi-T - are loosely based on these ideas [12]. Dimi-S was also called Sexophone or Kärlekmaskinen (Love Machine in Swedish). It is played by

\footnotetext{
${ }^{1}$ http://www.beige.org/projects/dimi/
} 


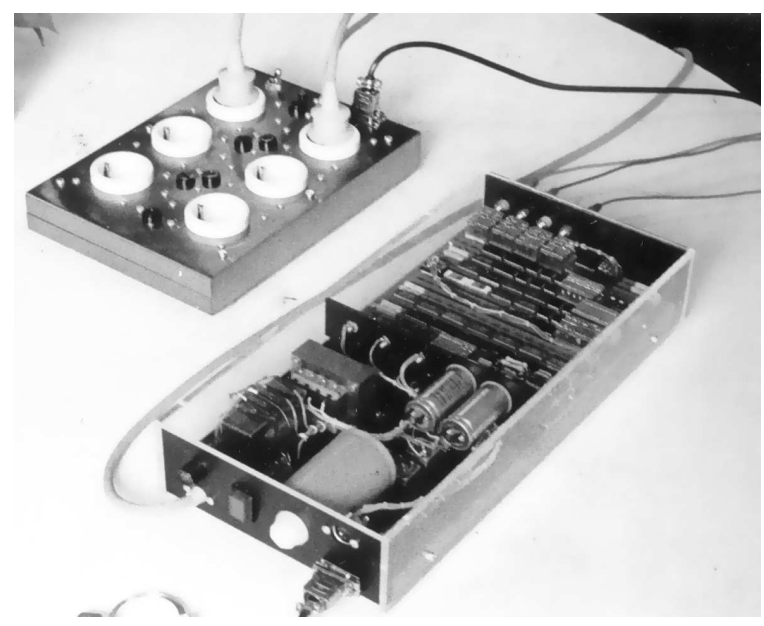

Figure 6: Dimi-S

four people holding iron balls in their hands. Ralph Lundsten, who ordered the instrument, used it in some art exhibitions and just "for fun" [8]. Two copies of the instrument were made and they are both located in Lundsten's Andromeda studio together with the only manufactured DimiO unit.

The control signal of Dimi-S is constructed from the changes in the electroresistance of human skin when people are touching each other. The iron balls are connected to the Dimi-S main unit (figure 6, right). Dimi-S also contains a light organ unit (figure 6, left).

Dimi-T ( $\mathrm{T}$ stands for thinking) is based on the idea of alpha waves produced by the human brain while sleeping as a control signal of the instrument. The user attaches electrodes on his scalp and the EEG (electroencephalogram) signal is measured. Then the EEG signal is used for controlling the pitch of an oscillator.

\section{TECHNICAL DESIGN PRINCIPLES}

Kurenniemi has experimented with digital circuits with almost all of his electronic musical instruments. However, the design and functionality of these synthesizers do not have much in common e.g. with digital synthesizers of the 1980's. Some of the techniques Kurenniemi has exploited on his instruments are common in analog synthesizers and electric organs.

Like the earliest electronic musical instruments, Kurenniemi's devices demand some engineering skills from the musician operating them. Kurenniemi's instruments being mostly experimental prototypes, the user interface does not hide the inner design of electrical circuits, and, indeed, the circuits themselves have clearly had a strong influence on the user interface design of these instruments.

With Integrated Synthesizer Kurenniemi started to experiment with digital circuits. The synthesizer has digital logic ports from which the user can build different digital circuits, such as different sequencers, using a set of five patch matrices (of the same type as the EMS VCS3 synthesizer patch matrix). Many of the digital circuits that Kurenniemi used in his later synthesizers are probably results of the experiments made with Integrated Synthesizer.

Kurenniemi built a sequencer into most of his synthesizers. The simpler ones are quite similar to Buchla's classic design based on a single shift register. However, Kurenniemi was interested in automating the whole music reproduction process. Therefore he expanded the basic logic of a sequencer with some simple designs. The first step was to exploit digital counter circuits (Electric Quartet and Andromatic) with which the operator of the instrument could produce long sequences with modulations on the melody. The sequencer in Andromatic is a clever design where the state of a flipflop on each sequencer stage can be set to either break, shift register or counter mode.

In the late 1960's, Kurenniemi started to experiment with digital memory circuits. Dico was the first synthesizer to have a digital memory. It allowed to store 10 parameters into each of its 12 sequencer steps. This design was further developed in Dimi-A, which uses an associative memory scheme by making it possible to save up to 100 musical events, which could happen on any moment in an up to 256 step long sequence.

Frequency division, a commonly used technique in electric organs, was used on Dico, Dimi-A, and Dimi-O. During 1960 's, the stability of oscillators was still a major problem among synthesizer designers and frequency division offered a simple way to keep an instrument in tune as it requires only one oscillator, which does not need to be voltage controlled (the most common electric organ design uses 12 oscillators, one for each note of an octave) [13]. The oscillator is tuned above the audible frequency range and all the notes of the synthesizer are made by dividing the frequency with whole numbers $[14,1]$. The technique is easiest to implement when the waveform of the signal is a pulse wave and therefore it is the waveform of choice in most of Kurenniemi's instruments.

Besides the frequency division network, the ring modulator and the attenuator circuits of Dimi-A are "quasi-digital" designs which are using digital logic ports and can therefore process only digital waveforms.

\section{USER INTERFACE ASPECTS}

The design of Kurenniemi's electronic musical instruments is based mainly on the components that were available at the time and on the ideas he got from the contemporary electronic component catalogues [3]. On the other hand, his instrument design is based on a very open-minded and experimental attitude regarding the user interface. Furthermore, Kurenniemi was prone to exploit unconventional methods for controlling and programming the instruments (e.g. optical input or biofeedback).

The user interfaces of Kurenniemi's first instruments were very technically oriented, reflecting the technical functionality at the hardware level. Therefore, the input mechanism was mainly 'plug in' type. Partly this is reflecting the fact that the first instruments were tailor-made and he knew who would be operating them. However, Kurenniemi interestingly did not choose to use a conventional musical instrument user interface (e.g. a keyboard) even in his later innovations where he had clearly put some thought upon the user interface design and usability. The Dimi-A user interface clearly shows attempts to create an aesthetic and attractive user interface the overall user experience in mind - there was also a graphic designer involved in the first steps of the design work. That reveals what a forerunner Kurenniemi was, since aesthetics and attractiveness have only lately gained attention in the usability area. $[9,18,7]$ 
The downside of choosing unconventional user interface solutions is that the instruments did not look familiar and therefore it was probably harder to get financial support and arouse interest in potential markets. If Kurenniemi had chosen to pack the equipment e.g. into a cover of an electric organ, the public's and financiers' interest might have been more significant.

Although the Dimi-A user interface looks attractive, the usability of the instrument is still quite unsatisfactory: the user needs to remember what s/he has done, i.e. what parameters were chosen. The user interface won't give nearly any feedback from the user's choices, which is regarded as one of the main usability criteria in any user interface. However, Kurenniemi continued being very innovative with some of his later instruments: for example, with Dimi-O he presented an idea of reading notes with a video camera, and then playing the music in question (nowadays the concept of e.g. reading EAN-like codes digitally is widely spread). With Dimi-S the input technique was people touching each other. With Dimi-T Kurenniemi presented the idea of using EEG as an input method (we only start to see equipment using EEG as an input signal now).

\section{CONCLUSIONS}

The evolution of Kurenniemi's instrument designs may be regarded as a logical and gradual transition from analog to "quasi-digital" to digital electronics. In his electronics designs, Kurenniemi was more interested in programmability than in sonic flexibility or in developing novel synthesis techniques. In particular, Kurenniemi did not implement a purely digital sound synthesis system in any of his early or Dimi instruments. However, his user interface designs were greatly influenced by digital logic. This, combined by the lack of conventional control hardware, such as a piano-style keyboard (Dimi-O being the only exception), made adoption of these instruments difficult for ordinary musicians.

Despite their unconventional user interfaces, there is something appealing and fascinating in many of the instruments. In particular, the compact size and the austere but visually balanced user interface of Dimi-A, have made it a classic and gained it status as a work of art. The inter-artistic optical interface of Dimi-O and the somewhat provocative skin resistance interface of Dimi-S alone earned Kurenniemi a reputation of an eccentric artist and scientist. In some aspects, Dimi-S and Dimi-O remind us of the electronic instruments of Lev Sergeyevich Termen, a.k.a. Léon Theremin. On the other hand, the microprocessor based Dimi-6000, Kurenniemi's most flexible and technically advanced instrument, appeared only as a conventional CRT terminal and a set of stacked aluminum boxes.

Kurenniemi's visions often went beyond what was possible to implement with contemporary technology or what was financially realistic at the time. He was, nevertheless, successful as an instrument designer having completed a total of 9 different musical devices between 1968 and 1973. Since the marketing attempts for the Dimi instruments failed, and in spite of Kurenniemi's many appearances in the Finnish mass media, his instruments remained fairly unknown until the late 1990's when the Finnish electronic music scene adopted him as their forerunner and "godfather". As a result, Kurenniemi was celebrated as the guest of honor and featured artist of the 2002 Avanto international media art festival in Helsinki. There, many of his instruments were played live, perhaps for the largest audience ever.

Most of Kurenniemi's instruments have survived to present day and many of them are still in working order. The remaining instruments in Finland are stored, and occasionally used, in the Electronic Music Studio at the Department of Musicology, University of Helsinki.

\section{REFERENCES}

[1] A. Douglas. The Electronic Musical Instrument Manual. 6. edition. Pitman publishing, London, 1976.

[2] P. Kuljuntausta. On/Off: eetteriäänistä sähkömusiikkiin. Like, Helsinki, 2002.

[3] E. Kurenniemi. Taped interview by Mikko Ojanen and Jari Suominen, Helsinki, 29 May 2004.

[4] E. Kurenniemi. Elektronisen musiikin instrumenteista. Musiikki, 1:37-41, 1971.

[5] E. Kurenniemi. Musical harmonies are divisor sets. In Proceedings of Nordic acoustical meeting 88, pages 371-374, Tampere, 1988.

[6] E. Kurenniemi. Erkki Kurenniemi: äänityksiä/recordings: 1963-1973. Siboney, Helsinki, 2002. CD.

[7] M. Kurosu and K. Kashimura. Apparent usability vs. inherent usability: experimental analysis on the determinants of the apparent usability. In $\mathrm{CHI}$ '95: Proceedings of the SIGCHI conference on Human factors in computing systems, pages 292-293, 1995.

[8] R. Lundsten. Taped interview by Jari Suominen, Stockholm, 8 June 2004.

[9] D. Norman. Emotional Design. Basic Books, New York, 2003.

[10] M. A. Numminen. Taped interview by Jari Suominen, Helsinki, 7 October 2006.

[11] M. Ojanen. Jukka Ruohomäen sävellystuotanto ja tyylipiirteet 1970-luvulla: Esimerkkianalyysi teoksesta Pisces. Master's thesis, University of Helsinki, 2007.

[12] M. Ojanen and J. Suominen. Erkki Kurenniemen sähkösoittimet. Musiikki, 3:15-44, 2005.

[13] T. Pinch and F. Trocco. Analog Days: The Invention and Impact of the Moog Synthesizer. Harvard University Press, November 2004.

[14] T. Rossing. Science of Sound, 2. edition. Addison-Wesley, New York, 1990.

[15] J. Ruohomäki. Taped interview by Mikko Ojanen, Jari Suominen and Kai Lassfolk, Helsinki, 4 December 2004.

[16] M. Taanila. Future is not what it used to be. Kinotar, Helsinki, 2002. DVD.

[17] K. Tiits. Voluntääriassistentti Kurenniemi ja elektronimusiikin alku yliopistolla. Master's thesis, University of Helsinki, 1990.

[18] N. Tractinsky. Aesthetics and apparent usability: empirically assessing cultural and methodological issues. In CHI '97: Proceedings of the SIGCHI conference on Human factors in computing systems, pages 115-122. ACM Press, 1997.

[19] H. Viitasalo. Taped interview by Mikko Ojanen and Jari Suominen, Vantaa, 4 November 2004. 